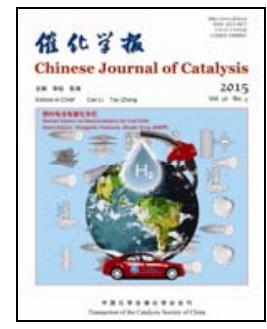

Editorial (Special Column on Electrocatalysis for Fuel Cells)

\title{
Preface to Special Column on Electrocatalysis for Fuel Cells
}

This special column is to host scientific contributions in electrocatalysis. It covers the range from fundamental to applied research and aims to open a "window" into this field. As is well known, heterogeneous catalysis and electrocatalysis are related. Both use well-controlled sequences of elementary bond breaking and making processes, and they share many common mechanistic principles in the use of supported metal and metal oxide catalysts. Electrocatalysis is a subfield in electrochemistry that has seen special growth in the last thirty years due to new hybrid applications and techniques. However, most of these have mainly academic significance but have less technical use in industry. Currently, the application of the new concepts of electrocatalysis in industrial electrochemical processes has become a necessity that attracts the attention chemists and engineers.

Among the most important applications of electrocatalysis are fuel cells. However, the many fundamental catalyst limitations that have plagued fuel cells for more than a century still remain. The main objective of this special column is to provide a carefully balanced selection of the advances in fuel cell science and technology. There are seven contributions (2 reviews and 5 research papers) devoted to new materials and their applications in both proton exchange membrane fuel cells and solid oxide fuel cells. All contributors are well known scholars in the field of electrochemistry and fuel cell science and technology.

We are grateful to Professor Liwu Lin (Editor-in-Chief of the Forth Editorial Board of Chinese Journal of Catalysis) and Professor Qin Xin (Advisor) of Chinese Journal of Catalysis for their invitation to be the guest editors of this special column. We are also grateful to all our colleagues who contributed with enthusiasm to this special column. We thank them for their responsibility and their high quality manuscripts. Unfortunately, due to limited time, we were not able to invite many other contributions to this special column. However, we deeply hope that in the future, scientists from all over the world will choose to submit their excellent studies on electrocatalysis (for example, works on new catalysts and electrocatalysts for fuel cells) for publication in Chinese Journal of Catalysis.

On the occasion of his $65^{\text {th }}$ year, we dedicate this special column to Professor Costas Vayenas for his outstanding contributions to the field of catalysis and electrocatalysis.

Finally, the Guest Editors gratefully acknowledge the staff of the editorial office of this journal for their dedication to this special column and their careful and earnest work.

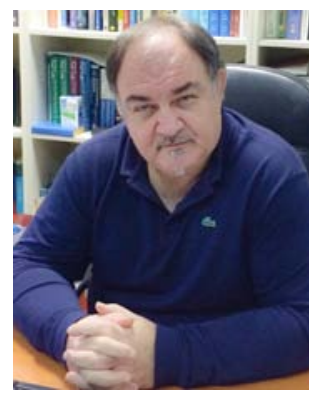

Professor Panagiotis Tsiakaras

(Guest Editor)

Department of Mechanical Engineering,

School of Engineering,

University of Thessaly,

Volos 38334, Greece

E-mail address: tsiak@uth.gr

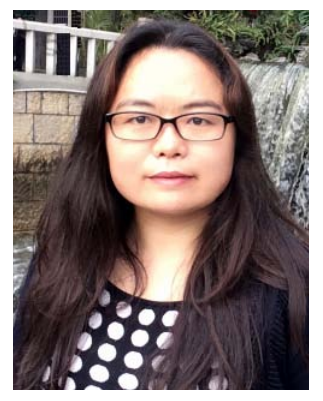

Professor Shuqin Song (Guest Editor)

School of Physics and Engineering,

Sun Yat-sen University,

Guangzhou 510275, Guangdong, China

E-mail address: stsssq@mail.sysu.edu.cn 